
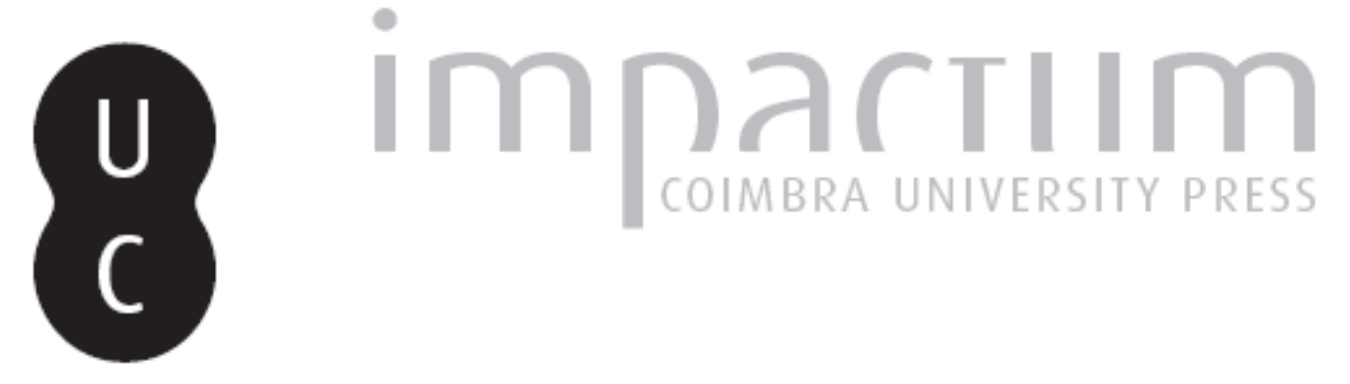

\title{
Empirismo construtivo e realismo ontológico
}

\author{
Autor(es): $\quad$ Araújo, Rodolfo Petrônio da Costa
}

Publicado por: $\begin{aligned} & \text { Universidade Católica de Petrópolis; Instituto Brasileiro de Informação } \\ & \text { em Ciência e Tecnologia }\end{aligned}$

URL

persistente:

URI:http://hdl.handle.net/10316.2/33041

DOI:

DOI:http://dx.doi.org/10.14195/1984-6754_3-2_5

Accessed : $\quad$ 26-Apr-2023 11:32:37

A navegação consulta e descarregamento dos títulos inseridos nas Bibliotecas Digitais UC Digitalis, UC Pombalina e UC Impactum, pressupõem a aceitação plena e sem reservas dos Termos e Condições de Uso destas Bibliotecas Digitais, disponíveis em https://digitalis.uc.pt/pt-pt/termos.

Conforme exposto nos referidos Termos e Condições de Uso, o descarregamento de títulos de acesso restrito requer uma licença válida de autorização devendo o utilizador aceder ao(s) documento(s) a partir de um endereço de IP da instituição detentora da supramencionada licença.

Ao utilizador é apenas permitido o descarregamento para uso pessoal, pelo que o emprego do(s) título(s) descarregado(s) para outro fim, designadamente comercial, carece de autorização do respetivo autor ou editor da obra.

Na medida em que todas as obras da UC Digitalis se encontram protegidas pelo Código do Direito de Autor e Direitos Conexos e demais legislação aplicável, toda a cópia, parcial ou total, deste documento, nos casos em que é legalmente admitida, deverá conter ou fazer-se acompanhar por este aviso.

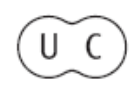



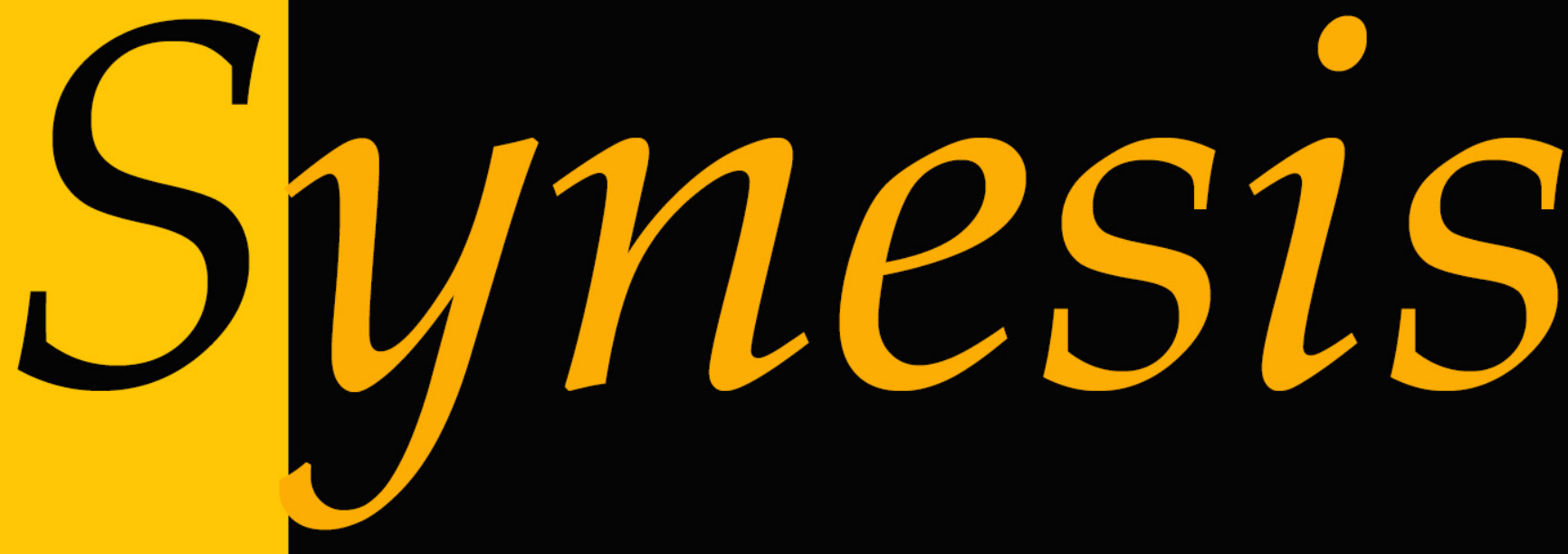

Revista do Centro de Teologia e Humanidades ISSN 1984-6754

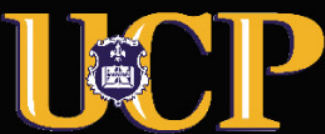




\title{
EMPIRISMO CONSTRUTIVO E REALISMO ONTOLÓGICO ${ }^{1}$
}

\author{
Rodolfo Petrônio da Costa Araújoº
}

Resumo: O objetivo principal deste artigo é mostrar a necessidade de uma análise ontológica da natureza, em aditamento à fornecida pela ciência experimental. Para tanto, defendemos que o objetivo central de nossas teorias científicas é obter adequaçáo empírica, perspectiva que se encontra bem consubstanciada na proposta do empirismo construtivo de Bas van Fraassen. No entanto, o caráter semântico de adequaçáo empírica das teorias científicas apresentado pelo empirismo construtivo náo é suficiente para que se obtenha um conhecimento integral da realidade natural, cuja contraparte mais conceitual e qualitativa deve ser fornecida pela perspectiva ontológica a que nos referimos. Esta análise ontológica é um realismo, porém este, contrariamente às diversas propostas do realismo científico, tanto reivindica que as teorias científicas não possuem alcance ontológico como igualmente que elas náo provêem de fato uma descrição literal da essência do mundo, não obstante serem en bloc verdadeiras acerca do que se pode observar ou medir em termos quantitativos. Sugere-se, por conseguinte, o uso articulado dos dois métodos de análise, experimental e ontológico.

Palavras-chave: Empirismo construtivo; Realismo; Filosofia da ciência; Bas van Fraassen.

Abstract: This article mainly aims at showing that an ontological analysis of nature is needed, in addition to the one provided by experimental sciences. For this intent, we claim that the central objective of our scientific theories is reaching empirical adequacy; such a point of view has been quite well founded within the constructive empiricist proposal by Bas van Fraassen. Van Fraassen empirical adquacy semantic feature in constructive empiricism, however, doesn't suffice to grasp a whole understanding of natural reality, whose most conceptual and qualitative balance should be given by an ontological view. This latter is a realism, but inversely to the various scientific realism views, both claims that scientific theories do not have an ontological grasp and do not provide us with a litteral description of what the world is like, notwihstanding being en bloc true on what one can quantitatively observe ou measure. Thus both methods are suggested to be carried out in an articulated way: experimentation and ontology.

Keywords: Constructive empiricism; Realism; Philosophy of science; Bas van Fraassen.

\footnotetext{
${ }^{1}$ Artigo recebido em 17/10/2011 e aprovado para publicação pelo Conselho Editorial em 19/11/2011

${ }^{2}$ Doutor em filosofia pela Pontifícia Universidade Católica do Rio de Janeiro. Professor da Universidade Federal do Estado do Rio de Janeiro (UNIRIO). Currículo lattes: http://lattes.cnpq.br/3054995551617079. Email: rodolfo.petronio@gmail.com.
} 


\section{Introduçáo}

Com o nascimento do método experimental-matemático, característico da ciência moderna, o conhecimento e a doutrina dos clássicos sobre a natureza ficaram numa situaçáo epistemológica difícil de ser sustentada. O êxito da nova ciência no domínio dos fenômenos naturais, e que se delineava entre os séculos XVI e XVII através de gigantes como Galileu, Kepler e Newton, assim como sua oposição polêmica ao antigo sistema clássico aristotélico e sua filosofia da natureza, favoreceu o entendimento da nova ciência como vantajosa frente àquele antigo sistema. A modernidade estabeleceu então um problema epistemológico de grande envergadura, haja vista que a ciência moderna transformou o modo como pensamos o mundo. A natureza náo é mais considerada como aquilo que nossos sentidos indicam. Considera-se que entes e processos invisíveis a olho nu, tais como ondas eletromagnéticas, elétrons, prótons, fótons, quarks, neutrinos, genes e moléculas de DNA, para citarmos apenas uns poucos, são componentes do mundo e causam grande parte dos fenômenos observáveis. Por que devemos considerar as teorias científicas como verdadeiras, ou aproximadamente verdadeiras? Por que devemos crer que todos os entes postulados por nossas melhores teorias sejam reais? Por que não considerar que essas teorias náo passam de simples instrumentos para a sistematização e a predição dos fenômenos observáveis? Ou, talvez, suspender nosso julgamento quanto à verdade de seus enunciados sobre a existência daqueles entes e processos inobserváveis e crer que as teorias são empiricamente adequadas, isto é, que apenas o que elas enunciam sobre observáveis, e apenas sobre estes, é verdadeiro?

O tema da relação entre ciência e filosofia constitui-se num elemento crucial para compreendermos o espírito do pensamento contemporâneo em várias instâncias. Uma boa parcela dos sistemas filosóficos a partir de Descartes aparece, direta ou indiretamente, condicionada pelo modo de estabelecer o alcance da ciência, chegando-se muitas vezes a apresentá-la como paradigma de todo conhecimento verdadeiro, ou como fator decisivo para julgar os principais problemas teóricos e práticos da filosofia. Muitas direçóes filosóficas nos últimos dois séculos (o empirismo, o positivismo lógico do Círculo de Viena, a filosofia analítica, etc.) são fruto de uma determinada reflexão sobre a ciência e sobre o método científico, ou pelo menos neles buscam sua justificação. 
Por sua vez, essa reflexão suscitou posiçóes, e conseqüentemente reaçóes, de diversos matizes epistemológicos. No entanto, podemos, em linhas gerais, classificar as posições em duas vertentes antagônicas (porque elas são antagônicas é o que buscaremos esclarecer ao longo deste trabalho): o realismo e o anti-realismo científicos. $\mathrm{O}$ adjetivo científico supóe que os debates situar-se-ão em torno da reflexão filosófica sobre a ciência, e, especialmente nas últimas décadas, polarizaram-se as posiçôes, situação favorecida pelo declínio da escola positivista, em parte devido aos avanços dos sistemas teóricos propostos pela física contemporânea, que suscitou na reflexão filosófica uma ampla tendência metafísica e epistemológica agrupada sob uma bandeira chamada de realismo científico, e pelo aparecimento de uma crítica contundente e extraordinariamente bem elaborada a este último, empreendida por Bas C. van Fraassen, exposta em seu livro The Scientific Image (Oxford, 1980), no qual propóe uma concepção filosófica alternativa e sistemática sobre a ciência chamada de empirismo construtivo.

Visamos como objetivo central de investigação estabelecer os limites de validade ou de verdade, bem como sua mútua relação, da proposta anti-realista de van Fraassen ou empirismo construtivo, de natureza marcadamente epistemológica, e uma proposta realista de enfoque ontológico, que denominamos análise ontológica. Pretendemos igualmente examinar a possibilidade de o empirismo construtivo descrever o ideal epistemológico da ciência experimental, mormente a física, bem como de o realismo ontológico suprir-lhe a contrapartida ontológica. Por serem ambos, a nosso ver, enfoques complementares, tanto com respeito ao papel que as teorias científicas desempenham no conhecimento do mundo natural (teses axiológicas), quanto com relaçáo à postura do cientista acerca do alcance da ciência (teses epistêmicas), a uma, descrita pelo enfoque van frassiano, chamaremos de análise empiriológica, e à sua contraparte ontológica, denominaremos análise ontológica, à qual já nos referimos acima. Cabe observar também que a proposta de van Fraassen é relativamente conhecida, o que se reflete na exposição mesma desta proposta. Por outro lado, um realismo de cunho ontológico (ou metafísico) tem sido pouco explorado no papel de contraparte do empirismo construtivo, uma vez que o próprio van Fraassen rechaça qualquer compromisso ontológico para as ciências experimentais. No entanto, se tomarmos a contraparte ontológica de van Fraassen como náo pertencente ao domínio das ciências experimentais, mas se caracterizando como um outro tipo de conhecimento, cuja possibilidade e natureza pretendemos explorar 
nessa investigação, então o empirismo construtivo ficaria impossibilitado de rechaçar por completo a pretensão ontológica de sua contraparte.

\section{Realismo e anti-realismo científico}

Nossas teorias científicas reivindicam, ou ao menos parecem reivindicar, que o universo está povoado por uma multidão de entes que não podemos observar de forma trivial: genes, fótons, quarks, espaço-tempo curvo, etc. Estaríamos (incluindo os cientistas) justificados em crer na existência desses entes? Os realistas científicos dizem que sim -- que tais entes realmente existem $^{3}$--, ao passo que os anti-realistas dizem que não ${ }^{4}$. O realismo científico, em linhas gerais, defende que a realidade se identifica com a coleção de todos os entes concretos, ou reais. Postula a existência autônoma do mundo externo e nos encoraja à descoberta deste, tendo como pressuposto que isto é perfeitamente possível. Com esta busca, enriquece a totalidade das verdades factuais, ou empíricas, sobre a realidade, ou o mundo. Embora o conceito de verdade seja central para o realismo científico, este não envolve necessariamente a suposição de que a verdade seja completa, isto é, que uma demanda última por explicação ${ }^{5}$ seja sempre alcançada. Do ponto de vista epistêmico, buscamos tais verdades, e, em alguns casos, reivindicamos que as mesmas são obtidas de forma aproximada, sendo corrigidas posteriormente, num processo continuado de pesquisa e correçáo. Há pontos que os realistas em geral sustentam, portanto, acerca de nossas teorias científicas:

- Que podem ser avaliadas como sendo quer verdadeiras, ou apenas aproximadamente verdadeiras.

\footnotetext{
${ }^{3}$ Cf. PSILLOS, 1999, p.3.

${ }^{4}$ Há diversos matizes com entre os antirealistas com respeito ao papel desempenhado por entes inobserváveis. Por exemplo, Carnap, em sua primeira fase de elaboração positivista, defendia a redução dos entes inobserváveis por via sintática a entes observáveis. Propôs que um termo teórico $\mathrm{T}$ se aplica a um objeto $\mathrm{x}$ se e somente se ao $\mathrm{x}$ satisfazer certas condiçóes $S$ de teste, então x apresentaria a resposta observável $\mathrm{O}$. Em termos sintáticos, teríamos $\forall \mathrm{x}(\mathrm{T} \mathrm{x} \leftrightarrow(\mathrm{S} \mathrm{x} \rightarrow \mathrm{Ox}))$. (cf. PSILLOS, 1999, p. 4). Já Duhem, ainda na segunda década do século XX, submetera à Academie dês Sciences um relatório que se constituía num longo ensaio dividido em três partes; numa delas, a segunda, Duhem expôs sua posição, em comparação com diversas filosofias da ciência à época, tecendo algumas importantes consideraçôes sobre a natureza dos entes teóricos. (cf. DUHEM apud ARIEW \& BARKER, 1996, p.232-238).

${ }^{5}$ MUSGRAVE (1985) identifica a crença numa demanda última por explicar a realidade com uma posição essencialista.
} 
- Que, por isso, objetivam a verdade, ou uma aproximação da verdade.

- Que seu êxito é evidência que conta a seu favor como sendo realmente verdadeiras.

- Que, se verdadeiras, os entes inobserváveis postulados pela ciência, por exemplo elétrons, fótons, quarks, campos, etc. realmente existem.

- Que, se verdadeiras, elas teriam poder explicativo, isto é, responderiam a uma demanda por explicação, ao buscar explicar os fenômenos observáveis.

De modo um geral, não há oposição relevante entre realismo e anti-realismo quando estamos tratando de objetos comuns de nossa experiência: livros, mesas, bolas de bilhar, etc. Ora, tais entes são percebidos por nossos sentidos, e há todo um processo cognitivo envolvido o qual não é objeto de nosso trabalho. Porém, há uma forma de anti-realismo evidente que é o ceticismo com respeito ao conhecimento desses objetos ordinários da experiência. Ora, isto se torna ainda mais complexo quando pleiteamos obter conhecimento sobre objetos náo ordinários de nossa experiência, tais como átomos, etc. Richard $\mathrm{Boyd}^{6}$ apresenta-nos, sob a forma de modalização semântica, metafísica e epistemológica, as teses que estariam envolvidas no realismo científico:

- Realismo semântico: os termos teóricos que aparecem nas teorias científicas, isto é, termos náo-observacionais, devem ser tratados como referências a realidades supostas como existentes, e as teorias devem ser interpretadas realisticamente.

- Realismo metafísico: a realidade que as teorias científicas descrevem é amplamente independente de nosso pensamento ou de nossos compromissos teóricos.

- Realismo epistemológico: as teorias científicas, interpretadas realisticamente, são confirmáveis, ou, com efeito, freqüentemente confirmadas como aproximadamente verdadeiras.

Por outro lado, o anti-realismo científico apresenta diversos matizes pelos quais se opóe ao realismo, entre eles negar quer o estatuto ontológico dos entes teóricos postulados por nossas teorias científicas, quer a verdade dessas teorias. Por exemplo, uma das abordagens antirealistas, em sua reflexão filosófica sobre a ciência, vê as teorias e seus construtos (propriedades, relações, entes teóricos, etc.) como sendo recursos de um determinado sistema

\footnotetext{
${ }^{6}$ Cf. BOYD, 1983.
} 
lingüístico; neste caso, perguntas filosóficas, quer sobre a verdade ou falsidade das teorias quer sobre a existência ou a realidade de seus construtos, não possuem significado senão na própria linguagem ${ }^{7}$. Outras abordagens anti-realistas defendem que o objetivo das teorias, e, por conseguinte, dos entes teóricos que postulam, é unicamente salvar os fenômenos ${ }^{8}$, ou seja, obter adequação empírica. Tais entes teóricos não passariam, portanto, de dispositivos pragmáticos postulados pelas teorias, e sua existência ou é negada ou é tida como incognoscível (agnosticismo com respeito aos entes teóricos). Por conseguinte, as teorias num caso ou noutro se desobrigam de compromissos ontológicos. Talvez pudéssemos, em linhas gerais, semelhantemente ao que fez $\mathrm{Boyd}^{9}$, apresentar as teses do anti-realismo sob as três modalidades, semântica, metafísica e epistemológica, como sendo:

- Anti-realismo semântico: os termos teóricos que aparecem nas teorias científicas não se referem a entes inobserváveis que existem independentemente de nosso pensamento, como usualmente assumimos que de fato o façam.

- Anti-realismo metafísico: os entes inobserváveis não existem.

- Anti-realismo epistemológico: não sabemos se estamos justificados em crer na verdade de nossas teorias científicas.

\section{O empirismo construtivo de Bas van Fraassen}

Van Fraassen apresentou ${ }^{10}$ uma alternativa empirista ao realismo científico e ao positivismo lógico. Para van Fraassen, uma posição anti-realista em ciência, propriamente empirista, seria:

Ser um empirista significa não demonstrar crença em algo que se situe além dos fenômenos reais, observáveis. Desenvolver uma medida empirista da ciência significa retratá-la como envolvendo uma busca pela verdade unicamente acerca do mundo empírico, sobre o que é real e observável. ${ }^{11}$

\footnotetext{
${ }^{7}$ Cf. CARNAP, 1956.

${ }^{8}$ Cf. DUHEM, 1996, p. 131-156.

${ }^{9}$ Cf. BOYD, op. cit..

${ }^{10}$ Posição apresentada em seu livro The Scientific Image, como já mencionamos (Cf. VAN FRAASSEN, 1980).
} 
Ora, esta afirmação de van Fraassen vai claramente de encontro ao espírito característico do realismo científico. Apresentemos, portanto, o núcleo da tese de van Fraassen, por ele chamado de empirismo construtivo, o qual se expressa da seguinte forma: "A ciência objetiva nos dar teorias que são empiricamente adequadas; e a aceitação de uma teoria envolve unicamente a convicçáo de que ela seja empiricamente adequada." ${ }^{12}$ Temos, aqui, o eixo da tese de van Fraassen sobre o que almejam as teorias científicas. Para dar suporte à sua tese, van Fraassen nos apresenta duas questóes, ao mesmo tempo motivadoras e basilares de sua posiçáo: (a) o que é um modelo em ciência? (b) o que vem a ser o conterido empírico de uma teoria científica? Tendo respondido a estas duas perguntas, podemos mais apropriadamente expor sua posição, o empirismo construtivo.

Uma observação adicional: para van Fraassen, como será visto a seguir, modelo de uma teoria é definido a partir da lógica, ou seja, trata-se de um conceito lógico, que será utilizado para definir a adequaçáo empírica de teorias. No entanto, no linguajar dos cientistas, assim como no de filósofos da ciência que não estejam fazendo uso da definiçãao estritamente semântica de van Fraassen, modelo de uma teoria é uma representação matemática, muitas vezes constituída por elementos pictóricos, que nos auxilia na compreensão do fenômeno em estudo. Para distinguir modelo de uma teoria no sentido de van Fraassen, o qual possui implicaçóes semânticas, de modelo de uma teoria, no sentido usual, usaremos a notaçáo modelo- $L$, para o caso de um modelo lógico no sentido semântico de van Fraassen, e a notaçáo modelo- $R$, para o caso de um modelo representacional segundo o uso comum em ciência.

\section{Modelos lógicos e adequação empírica}

Primeiramente, vejamos uma tipificação de abordagem sintática de teorias e de como, a partir desta, podemos obter conseqüências testáveis. Desenvolvamos um exemplo de tratativa sintática: seja $T_{1}$ a teoria sob análise -- a qual requer comprovação --, $S_{1}$ o conjunto de pressupostos subsidiários que lhe é acrescentado com a finalidade de derivar alguns enunciados (em número finito) adicionais $T_{1}{ }^{\prime}$ que visem delimitar aproximadamente o campo

${ }^{11}$ VAN FRAASSEN, 1980, p. 202.

12 VAN FRAASSEN, 1980, p. 12. 
experimental de $T_{1}$. $\quad S_{1}$ inclui um modelo-R teórico do sistema -- ou dos sistemas -- em análise, possuindo talvez suposições simplificadoras, tais como linearizações. A teoria $T_{1}$, constituída por um conjunto infinito de enunciados, será julgada pelo desempenho dos teoremas $T_{1}{ }^{\prime}$, descritos na linguagem de $T_{1}$. Não é incomum que os teoremas $T_{1}{ }^{\prime}$ não sejam verificáveis de forma direta, pois podem envolver entes teóricos tais como campo ou tensão, que não possuem uma contrapartida empírica; neste caso, com a finalidade de fazer com a precisão necessária a ponte entre $T_{1}{ }^{\prime}$ e a experiência (visto que o conjunto subsidiário $S_{I}$ visou unicamente a que chegássemos próximos ao campo experimental da teoria), será necessário acrescentar um conjunto de hipóteses adicionais a que denominaremos referenciadores para os entes e propriedades inobserváveis em questão. Por exemplo: um inobservável como a gravidade é referenciada por movimentos. Seja $R_{I}$ o conjunto de referenciadores empregados para associar a teoria $T_{1}$ com a experiência. A esta altura, para evitar qualquer ligação dos elementos de $R_{I}$ com definiçôes operacionais, no sentido usual empregado pelo positivismo lógico, devemos observar que os elementos de $R_{1}$ são hipóteses desenvolvidas com base no conhecimento disponível -- que designaremos por $K$-- sobre a teoria em análise, com vistas a ajudar a definir detalhadamente que provas sáo cruciais para $T_{l}$. Devemos ser capazes de mostrar que as hipóteses referenciadoras devem estar bem fundamentadas, ou seja, que $K$ e $T_{I}$ conjuntamente nos levem ao conjunto adicional $R_{l}$. Ademais, precisaremos de enunciados empíricos particulares tais que sejam capazes de predizer resultados específicos. Seja $E_{I}$ o conjunto de dados experimentais que sustentam a teoria. Devemos, então, introduzi-los em $T_{1}$, o que demanda de nossa parte um esforço em traduzi-los adequadamente na linguagem com que está elaborada a teoria $T_{1}$. Exemplo: será necessário traduzir em coordenadas heliocêntricas aqueles dados astronômicos compilados originalmente em coordenadas geocêntricas. Designemos por $E_{1}{ }^{*}$ o conjunto de dados experimentais já expressos na linguagem de $T_{1}$. De posse das definiçóes acima, por meio de deduçóes puramente sintáticas, chegamos às conseqüências testáveis $T^{*}$-- isto é, empiricamente verificáveis -- da teoria $T_{1}$.

Mostramos, acima, um mecanismo descrito por Bunge ${ }^{13}$ com o objetivo de derivar sintaticamente as conseqüências testáveis de uma teoria, no qual aparece apenas um tipo de modelo, o representacional (modelo-R). No entanto, van Fraassen propóe uma alternativa à 
formulaçáo sintática descrita anteriormente para obter o que ele chama de adequação empírica. Segundo este autor, há limitaçóes na formulação sintática (mostramos um tipo possível de formulação, acima) para caracterizar as teorias científicas de forma adequada. Senão, vejamos:

(i) Primeiramente, uma teoria deve ser dedutiva, ou seja, possuir um conjunto de sentenças, os teoremas, formulados numa linguagem específica.

(ii) Tal vocabulário é dividido, como pudemos observar acima, em duas classes: os termos observacionais e os termos teóricos; o conteúdo empírico de uma teoria consiste em suas conseqüências testáveis, ou observacionais. Obviamente, duas teorias são empiricamente equivalentes se ambos os vocabulários contendo essas conseqüências observacionais são os mesmos.

(iii) No entanto, realizar uma distinção entre termos observacionais e termos teóricos nos conduz a sérias dificuldades sob esta ótica sintática, dado que as conseqüências testáveis de uma teoria significam apenas o que a teoria afirma sobre o que é observável, nada além disso. Mas, todo ente inobservável difere dos observáveis justamente porque lhe estáo ausentes, sistematicamente, características observáveis.

(iv) Temos, portanto, que dar conta, segundo a formulação sintática, de enunciar no vocabulário observacional (qualquer que seja este) que existem entes inobserváveis e de algum modo dizer como são eles.

(v) No entanto, por exemplo, se tomarmos a mecânica quântica segundo a interpretaçáo ortodoxa de Bohr, esta teoria implica a existência de objetos que ora possuem uma posiçáo no espaço ora náo. A Teoria de Newton implica a existência de algo, o Espaço Absoluto, que nem possui uma posição fixa nem ocupa volume. Tais conseqüências não se assemelham a nada que seja observável no mundo, nem nos dizem como seria algo que fosse observável.

(vi) Logo, as conseqüências testáveis (ou observacionais) não são uma descriçáo de parte do mundo formulada pela teoria, mas, antes, redundam ser uma descriçáo confusa de tudo que é formulado pela teoria.

Tudo isto parece indicar, pois, que a formulação sintática está incorreta e que "[...] talvez a pior de suas conseqüências tenha sido o fato de haver concentrado esforços em

${ }^{13}$ Cf. BUNGE, 2000, p. 182-186. 
questóes técnicas filosoficamente irrelevantes"14. Portanto, devemos desenvolver um outro tipo de abordagem diferente da abordagem sintática. A nova abordagem é semântica, e tem como uma de suas principais vantagens a possibilidade de reexaminar o problema da estrutura das teorias científicas -- ou de sua reconstrução racional -- à luz de uma nova ótica, que faz uso da noção lógica de modelo (modelo-L). Ademais, esta nova abordagem enseja uma particular fértil formulação de adequação empírica, essencial tanto para a proposta empirista de exame de teorias como de questóes ligadas à práxis científica. Substituamos, portanto, a formulaçáo sintática por uma formulação semântica, cujas linhas gerais são descritas a seguir.

Um modelo-L $M$ para uma determinada teoria é constituído por um domínio particular, isto é, um conjunto de objetos aos quais a teoria é, em princípio, aplicável, e por uma lista de relaçóes $n$-árias sobre os objetos do domínio. Suponhamos, ademais, um outro modelo-L $M^{*}$ imerso $^{15}$ no primeiro. Esta formulação na qual definimos modelos e relaçóes de imersão entre eles visa prover um mecanismo de inserir modelos- $\mathrm{L}$, denominados subestruturas empiricas, num modelo-L específico da teoria em exame. As subestruturas empíricas são aquela parte dos modelos- $\mathrm{L}$ candidatas a representar diretamente os fenômenos observados. A imersão é fundamental para definir com precisão o conceito de adequação empírica, em termos lógicos. Assim, a noção de adequação empírica envolve três componentes: um modelo-L de uma teoria, as subestruturas empíricas (subestruturas específicas do modelo-L), e o conteúdo observacional, ou empírico, descrito em relatos observacionais, as aparências. De forma concisa,

Apresentar uma teoria consiste em especificar uma família de estruturas, seus modelos $[-L]$; e, em segundo lugar, especificar certas partes daqueles modelos[L] (as subestruturas empiricas) como candidatas a representar diretamente os fenômenos observáveis. Às estruturas que podem ser descritas em relatos experimentais e de medição podemos chamá-las de aparências: a teoria é empiricamente adequada se possui algum modelo tal que todas as aparências sáo isomorfas a subestruturas empíricas desse modelo[-L $]^{16}$.

\footnotetext{
${ }^{14}$ VAN FRAASSEN, 1980, p.56.

15 Imerso no sentido de existir uma função que mapeia elementos do domínio de $M^{*}$ no domínio de $M$, preservando ademais as relaçóes existentes entre os elementos do primeiro, ou seja, que além de ser uma imersão seja também um isomorfismo entre os modelos.

${ }^{16}$ VAN FRAASSEN, 1980, p. 64.
} 
Podemos, agora, definir de modo mais preciso que uma teoria é empiricamente adequada se, para algum de seus modelos-L $M$, as aparências (ou dados observacionais) podem ser imersas neste modelo-L, ou seja, se existe um isomorfismo entre as subestruturas empíricas dadas e as aparências. Com base nesta caracterização semântica de adequação empírica, decorrem as demais noçôes da metodologia construtiva, tais como força empírica, equivalência empírica, etc., as quais exporemos com mais detalhe adiante. A formulação vista acima caracteriza um aspecto fundamental da abordagem do empirismo construtivo de van Fraassen, seu cunho semântico, em oposição à tratativa sintática, muito usual até então. Ou, segundo van Fraassen:

O quadro sintático de uma teoria a identifica com um corpo de teoremas, enunciados numa linguagem particular escolhida para expressar aquela teoria. Isto deve ser contrastado com a alternativa de apresentar-se uma teoria (...) identificando uma classe de estruturas como modelos[-L] seus. Nesta última abordagem, a semântica, a linguagem usada para expressar a teoria nem é básica, nem única; a mesma classe de estruturas poderia também ser descrita em formas radicalmente diferentes, cada qual com suas limitaçóes próprias. [Isto é] os modelos[-L] desempenham um papel central para a ciência. ${ }^{17}$

Van Fraassen nos alerta para o uso distinto que se faz do termo modelo em ciência ${ }^{18}$ (tal como já havíamos mencionado) como, por exemplo, o modelo de Bohr do átomo de hidrogênio. No caso ilustrado anteriormente, temos uma discussão que se situa no campo da lógica. Neste último, o do átomo de Bohr, não se trata de uma única estrutura mas de um tipo de estrutura, ou de classes de estruturas, todas elas -- cada tipo de átomo: de hélio, de hidrogênio, etc. -- compartilhando certas características gerais. É o que van Fraassen chama de um modelo-tipo (ou, segundo nossa notaçáo, de um modelo-R).

As teorias usualmente nos dizem muito mais do que aquilo que pode ser diretamente verificado por experimentos e observaçáo. A proposição "A teoria toda implica ..." indica-nos o conteúdo lógico da teoria. A parcela deste que pode, em princípio, ser verificado por experimento e observação é denominado o conteúdo empírico da teoria. Os termos que nos remetem a conceitos como experimento e observação carecem, no entanto, de especificação

${ }^{17}$ VAN FRAASSEN, 1980, p. 44. 
clara, dando margem a muitas definiçóes e pontos de vista sobre o que constitui o conteúdo empírico de uma teoria. Onde se encontra, nestes conceitos, a idéia de fenômeno? Por exemplo, modelos- $\mathrm{R}$ de dados, descrevendo padróes em larga escala de campos magnéticos fracos oscilatórios, não representam fenômenos no sentido em que van Fraassen atribui às aparências. Os modelos- $\mathrm{R}$ desses dados sáo cuidadosamente montados confrontando-se a resposta de magnetômetros extremamente sensíveis que são arrastados por embarcaçóes oceânicas, no intuito de obter os padróes de magnetizaçáo da plataforma oceânica, e depois rotacionados em torno de núcleos-padrão em laboratório (para obter a escala temporal de reversóes no campo magnético da Terra). Com efeito, as respostas que se obtêm desses magnetômetros devem ser consideradas o fenômeno observado. Por outro lado, essas respostas não são representadas sob forma alguma por qualquer parcela do modelo- $\mathrm{R}$ de camadas tectônicas da crosta terrestre. Supondo que os fenômenos se compóem naquilo que normalmente observamos em nosso entorno, incluindo os dados brutos ${ }^{19}$ produzidos por nossos instrumentos, o conteúdo empírico acaba sendo resultado de um esforço muito complexo envolvendo um sem número de especialidades e expertise técnico (e também de prática) que se apresenta como de difícil caracterização. Segundo Teller ${ }^{20}$, uma possível resposta de van Fraassen para esse tipo de complexidade, inerente a estabelecer o que deve contar como conteúdo empírico, e o papel dos instrumentos de medição na identificação do mesmo, seria: os instrumentos de medição são os objetos físicos que usamos em nossas investigaçóes científicas; no entanto, podemos expandir o que contamos como instrumentos de forma a incluir não apenas os indivíduos mas as instituiçóes que, de forma colaborativa, se envolvem na pesquisa científica. Podemos incluir, ademais, o comportamento e os produtos finais individuais e coletivos de cientistas como fenômenos. Aqui se inserem de forma relevante os modelos- $\mathrm{R}$ de dados que produzimos no processo de organizar, limpar e interpretar os dados brutos. Neste empreendimento, o resultado geralmente inclui objetos muito concretos tais como cartas astronômicas, histogramas que resumem resultados de estudos epidemiológicos relevantes a imunologia, e os diagramas que pensamos retratar as faixas de magnetizaçáo em

\footnotetext{
${ }^{18}$ Como mencionamos anteriormente, neste trecho van Fraassen faz a distinção entre modelos-L e modelos-R; a este último ele chama de modelo-tipo.

${ }^{19}$ Isto é, sem filtros adicionais construídos por análises e correçôes.

${ }^{20}$ Cf. TELLER, 2000.
} 
direçóes oscilantes na plataforma oceânica, e relevantes à teoria tectônica. Tais modelos- $\mathrm{R}$ de dados constituem o condensado de redes de teorias inter-relacionadas, assim como a expertise tanto matemática como tecnológica, produzidas no empreendimento coletivo da ciência. De qualquer forma, van Fraassen entende que o conteúdo (ou importe) empírico de uma teoria é definido a partir da ciência, por meio de uma distinção entre o que é observável e o que náo é observável, fornecido pela ciência ela própria, e enseja um compromisso epistêmico com a adequaçáo empírica que pode perfeitamente ser enunciado usando a linguagem científica vigente, ainda que esta esteja imersa num quadro teórico repleto de conceitos provenientes das teorias, sem que esta imersão impeça, contudo, que ponhamos entre parênteses as implicaçóes ontológicas das mesmas. ${ }^{21}$

Posto que van Fraassen defende o concurso de diversos fatores no sentido de definir o que seja o conteúdo empírico das teorias, decorre da abordagem semântica que acreditar numa teoria é acreditar que algum de seus modelos-L representa o mundo atual de forma correta. Como van Fraassen propóe, entáo, que duas teorias distintas podem ser empiricamente equivalentes, dada a complexidade que gira em entorno do conteúdo empírico de cada uma delas? Ele argumenta que cada modelo-L representa um mundo possível e que um desses mundos possíveis é o nosso mundo real. Sejam duas teorias rivais quaisquer que designaremos por $T^{*}$ e $T^{* *}$. Vejamos entáo em que consiste aceitar qualquer uma das teorias concorrentes. Ora, aceitar qualquer uma das duas teorias rivais introduzidas, $T^{*}$ ou $T^{* *}$, significa crer que, numa delas, um de seus modelos-L representa corretamente o mundo, não apenas em um de seus aspectos mas em todos eles. Em suma: em nosso caso, alguma das teorias, $T^{*}$ ou $T^{* *}$, apresenta uma subestrutura empírica $E_{1}{ }^{*}$ que é isomorfa a todos os fenômenos $A^{*}$. Porém se isto ocorre para cada uma delas, entáo $T^{*}$ e $T^{* *}$ devem igualmente, cada uma delas, possuir um modelo que salve nos mesmos termos todas as aparências $A_{1}^{*}$, o que as tornaria empiricamente equivalentes. Isto pareceria nos conduzir a um núcleo comum como caracterizador de teorias empiricamente equivalentes. No entanto, se as subestruturas empíricas

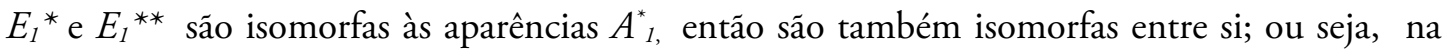
verdade, o conteúdo empírico (ou importe empírico) de ambas as teorias pode ser diretamente caracterizado nos mesmos termos em que é afirmada sua adequação empírica. Poder-se-ia

\footnotetext{
${ }^{21}$ Cf. VAN FRAASSEN, 1980, p. 81.
} 
objetar que, se fôssemos capazes de estender uma das teorias, $T^{*}$ ou $T^{* *}$, com vistas a abarcar novas demandas empíricas, sua equivalência empírica desapareceria e, neste caso, seríamos forçados a escolher aquela que possuísse um modelo- $\mathrm{L}$ que representasse adequadamente o mundo real, donde somente uma das teorias concorrentes seria verdadeira, o que tornariam inválidos os conceitos de equivalência e de adequação empíricas. Van Fraassen contraargumenta que não se pode assegurar que, ao estabelecer extensóes de antigas teorias com o propósito de salvar novas classes de fenômenos, o novo conteúdo empírico venha a por em xeque a adequaçáo da teoria estendida, de tal forma que a mesma seja interpretada entáo como sendo verdadeira e não mais como sendo táo-somente adequada à nova demanda empírica. Isto pode ser mostrado por meio de um exemplo tirado do eletromagnetismo clássico, baseando-se num experimento mental desenvolvido por Poincaré22. Este defendia que duas partículas eletricamente nulas, em aparente repouso na superfície da terra, deveriam atrair uma à outra pelo fato de ambas se encontrarem em movimento devido ao movimento de translação da Terra, este medido com respeito a algum referencial absoluto. Ora, a partir deste referencial absoluto, poderíamos, com base na força de atração desenvolvida pelas partículas, calcular a velocidade absoluta da Terra. É necessário esclarecer o seguinte: com o advento do eletromagnetismo, verifica-se, segundo as quatro equaçóes diferenciais de Maxwell ${ }^{23}$, que surgem forças entre corpos eletricamente carregados que dependem não apenas da aceleraçáo, como enuncia a mecânica clássica newtoniana, mas também da velocidade entre as partículas. Ora, a fim de que a mecânica de Newton pudesse ser estendida de forma a conter a nova classe de fenômenos representada pelo eletromagnetismo de Maxwell -- ou seja, salvar os fenômenos que ambas as teorias, em seus respectivos campos, realizavam com êxito --, tornava-se necessário postular a existência deste referencial absoluto para a medição de velocidades, referencial este a que se deu o nome de éter luminescente, capaz de estender o modelo mecânico de propagaçáo de ondas às novas ondas postuladas pelo eletromagnetismo de Maxwell. Estendendo-se a mecânica de Newton com o postulado de existência do éter luminescente, com suas propriedades mecânicas específicas, assim como já o tendo assumido como ente teórico implícito nas equaçóes de Maxwell, parecia-se resolver náo somente a disputa de teorias

\footnotetext{
${ }^{22}$ Cf. POINCARÉ, 1995, p. 118.
} 
empiricamente equivalentes em mecânica celeste, em favor daquelas que privilegiavam coordenadas absolutas como as estrelas fixas, por exemplo, como também aquelas teorias eletromagnéticas que privilegiavam descriçôes de tensóes e outros efeitos mecânicos no éter, em função da presença de ondas eletromagnéticas em movimento neste meio. Ademais, a extensão do modelo clássico confirmaria a teoria de Newton através do novo conteúdo empírico trazido pelo eletromagnetismo, o qual deveria adicionalmente conter os dados oriundos de um experimento que permitisse detectar o éter luminescente postulado. Porém, pela total ausência de comprovação experimental da presença de tal meio absoluto, o éter, e com o advento da teoria da relatividade, provou-se que, não apenas não havia tal referencial absoluto como também não era possível eliminar teorias rivais, porém empiricamente equivalentes, em mecânica e eletromagnetismo, com base em tal extensão. Van Fraassen vê neste exemplo de tentativa de eliminaçáo de teorias empiricamente equivalentes, acrescendo-se a hipótese do éter ao modelo clássico da mecânica newtoniana com vistas a tornar ambas as teorias verdadeiras, o fracasso da empreitada. Este fracassado exemplo de tentativa de eliminaçáo de teorias empiricamente equivalentes por meio da extensão de uma delas, de tal forma que a teoria estendida fosse verdadeira (ou aproximadamente verdadeira) segundo o realismo apenas serve para tornar ainda mais justificável a crença de que qualquer teoria científica seja apenas empiricamente adequada. Além do mais, qualquer extensão com vistas a abarcar uma nova classe de fenômenos somente torna a teoria empiricamente adequada ao novo importe observacional.

\section{Aspectos gerais da perspectiva construtiva}

Tomemos a definição do realismo científico conforme van Fraassen sugere, sob forma minimal, isto é, sob uma forma aceita pela maioria dos que defendem o realismo científico. Em primeiro lugar, o realismo científico caracteriza-se por objetivar uma descrição literalmente verdadeira $^{24}$ do mundo (perspectiva básica da posiçáo realista, ou ponto de vista axiológico $0^{25}$ ).

\footnotetext{
${ }^{23}$ As equaçóes de Maxwell estabelecem as leis da eletrodinâmica. Formam um conjunto de quatro equaçóes diferenciais, que regem a conservação e o movimento de partículas no campo eletromagnético.

${ }^{24}$ Cf. VAN FRAASSEN, 1980, p.8.
} 
Em segundo lugar, que a aceitação de uma teoria envolve a crença em sua verdade (perspectiva epistemológica). Vimos acima que o empirismo defende que as teorias unicamente salvam os fenômenos, isto é, que se ajustam aos eventos observáveis, ou dão conta de uma certa demanda empírica, em suma, que sejam empiricamente adequadas. Assim, a posição empirista não se compromete com aspectos ontológicos da realidade, isto é, com a existência de entes inobserváveis, subjacentes aos fenômenos. Ou seja, as teorias, através de modelos-L e de subestruturas empíricas que devem ser isomorfas aos fenômenos, buscam representar adequadamente o mundo, e, nesta operação de adequação, podem estar nelas inseridos conceitos tais como necessidade, probabilidade, etc. -- além de outros usuais tais como campo e spin --, que são tão-somente propriedades da linguagem, sem referência à realidade. Logo, podemos dizer que o empirismo construtivo defende uma espécie de agnosticismo com respeito aos entes inobserváveis. ${ }^{26}$ Observa van Fraassen que devemos distinguir, por um lado, o caráter teórico ou náo teórico dos termos e conceitos na linguagem das teorias, e por outro, as características observáveis ou não-observáveis dos entes: termos são teóricos ou não-teóricos (fazem parte da linguagem das teorias); entes, por sua vez, são observáveis ou inobserváveis. Há aqui, portanto, duas questôes diferenciadas: A primeira é saber se é possível distinguir na linguagem das teorias uma parte teórica constituída de termos puramente teóricos de outra parte não-teórica constituída de termos puramente observacionais. A segunda é saber se é possível classificar os objetos (entes) do mundo em observáveis e inobserváveis. $\mathrm{O}$ empirismo construtivo responde negativamente à primeira questão, ou seja, nossa linguagem científica está impregnada pela teoria, não se podendo fazer uma separaçáo clara entre termos teóricos e termos observacionais, e positivamente à segunda questão, ou seja, é possível fixar casos claros de entes observáveis e casos claros de entes inobserváveis. Esta distinção entre entes inobserváveis e entes observáveis é retomada no empirismo construtivo com muita força: tratase de uma posiçáo epistemológica que é relevante em van Fraassen, pois decorre do fato de as teorias, para serem empiricamente adequadas, apresentarem modelos e subestruturas empíricas que devem ser isomorfas aos fenômenos observados, e estes últimos devem ter sua constituição

\footnotetext{
${ }^{25}$ Cf. BUENO, 1999, p. 43.

${ }^{26}$ Neste ponto, se distingue de outras concepçóes empíricas as quais pretendem exorcizar toda e qualquer referência a inobserváveis, reduzindo-os a definiçóes operacionais envolvendo entes observáveis.
} 
clarificada pelos modelos, o que passa naturalmente por uma demarcaçáo entre o que pode ou não ser observado.

Descartado o aspecto redutivista do velho programa do positivismo lógico no que se refere ao aparato teórico das teorias, para o qual este poderia convenientemente ser reduzido a sentenças e termos puramente observacionais, resta, por outro lado, descartar a inseparabilidade entre teoria e observação, tese classicamente sustentada pelo realismo científico. Para van Fraassen, há o que parece ser um erro categorial quando se está discutindo sobre expressóes tais como entes teóricos ou a dicotomia teórico-observacional. Em primeiro lugar, termos ou conceitos são teóricos, introduzidos ou adaptados na construção das teorias. É bem verdade que seu uso se encontra táo disseminado em nossa linguagem comum que podemos dizer que esta se encontra contaminada com termos e conceitos provenientes de nossas teorias. ${ }^{27} \mathrm{O}$ modo como falamos, e também como os cientistas falam, é orientado por esquemas fornecidos por teorias já aceitas. Não cabe fazer uma reconstrução da linguagem nos moldes preconizados pelo positivismo lógico, higienizando-a da contaminaçáo por termos teóricos: este empreendimento está destinado ao fracasso. Em segundo lugar, devemos distinguir, numa outra categorização, entes teóricos (ou inobserváveis) de entes observáveis, que, segundo o empirismo construtivo, não ocorre apenas no âmbito da linguagem. Por exemplo, o termo observável discrimina entes possíveis (entes que podem ou não existir) como Pégaso, o cavalo voador (visto que se trata de um cavalo, é um ente observável, logo se tem certeza ao afirmar que não existe), do número dezessete, que é certamente inobservável, em qualquer instância ${ }^{28}$. Por isso, calcular a massa de uma partícula a partir de dados observados de sua trajetória, quando submetida a um campo de forças conhecido, de forma alguma é uma observação do ente massa. ${ }^{29}$ Adicionalmente, devemos clarificar, segundo van Fraassen, uma confusáo comum entre observar e observar que. Em ambas, está implícito o elemento percepção, porém somente numa delas, a segunda, está incluído o elemento informacional, o qual está vinculado, por sua vez, a um conceito e à sua envoltória cultural. Por exemplo, uma

\footnotetext{
${ }^{27}$ Cf. VAN FRAASSEN, 1980, p. 14. Trata-se de termos tais como: receiver VHF, massa, elemento, etc., cujo uso ocorre mesmo em reportes experimentais. Daí ser impossível uma reconstrução higienizada da linguagem científica sem esses termos, nos moldes em que preconizava o positivismo lógico.

${ }^{28}$ Cf. VAN FRAASSEN, 1980, p. 15.

${ }^{29}$ Loc. cit.
} 
bola de tênis ao ser observada por aborígines que vivem como se estivessem na Idade da Pedra, e por nós, que vivemos presentemente no mundo ocidental e estamos perfeitamente imersos na cultura atual: ambos (os aborígines e nós) observam a bola de tênis, porém somente nós observamos que é uma bola de tênis.

Feitas essas observaçóes, nos concentremos no argumento de van Fraassen contra a inseparabilidade teórica entre o observável e o náo-observável, como defendem realistas como Grover Maxwell ${ }^{30}$. Para este autor, observabilidade e inobservabilidade náo nos são dadas por critérios claros que permitam distinguir o que é teoria do que é observação. Por exemplo: suponha que se esteja olhando uma lâmina a olho nu; e em seguida, através de um microscópio de baixa resolução; em seguida, por um de mais alta resolução, e assim sucessivamente. Bem, nesta seqüência, observa Maxwell, não há critério claro que nos identifique, num dado instante da seqüência, que o ente que está sendo observado naquele ponto já seja o próprio ente a ser observado segundo a teoria, o que parece tornar impossível demarcar com precisáo a fronteira entre teoria e observaçáo. Van Fraassen contra-argumenta da seguinte forma: o fato de algo ser observável não significa que seja observado em algum instante. Retomemos o exemplo do microscópio: suponha que eu esteja analisando formigas muitíssimo diminutas. Tal tipo de formiga colocada na lâmina de observação pode de fato ser observado cada vez melhor com o aumento da resolução do microscópio, porém isto não significa que ao postular a existência deste tipo de formigas elas somente existam pelo fato de eu as poder observar através de um microscópio num dado instante: quer o microscópio esteja à disposição para a observação, quer não, as micro-formigas estarão aí para serem observadas. Por quê? Porque são o tipo de entes - tais como as luas de Júpiter -- que estão aí para serem observados, dado que as circunstâncias que permitam a observação sejam dadas. Por isso, van Fraassen nos mostra uma regra para a observabilidade de um ente qualquer $X$ : " $X$ é observável se existem circunstâncias tais que se $X$ se nos apresentar sob tais circunstâncias, então nós o observamos". ${ }^{31}$ Isso requer que sejamos igualmente capazes de apresentar casos claros de observabilidade e casos claros de inobservabilidade, uma vez que a regra acima não é propriamente uma definição, mas tãosomente uma guia. A proposta de van Fraassen, entáo, é definir um dispositivo de medição tal

\footnotetext{
${ }^{30}$ Cf. MAXWELL, 1962.

${ }^{31}$ VAN FRAASSEN, 1980, p. 16.
} 
que funcione como um medidor absoluto para nós seres humanos. Este dispositivo é o corpo humano, com suas potencialidades e limitaçóes naturais. Portanto, a aceitação de uma teoria como empiricamente adequada envolve reivindicar que o que a mesma afirma sobre o que é observável por nós é verdadeiro. Por outro lado, remeter a observabilidade para os seres humanos implica remeter as teorias a uma comunidade epistêmica ${ }^{32}$, dentro da qual dá-se a aceitação ou a rejeição dessas teorias. No âmbito da comunidade epistêmica (e científica) ocorre um choque adicional entre as propostas do realismo e a do empirismo construtivo. Este choque refere-se à forma de conceber a atividade científica em si mesma. Vimos que, para os realistas, a ciência objetiva nos fornecer um quadro ontologicamente verdadeiro do mundo; ora, sendo assim, a atividade científica consistirá na busca de teorias verdadeiras, ou seja, "teorias que capturem a estrutura do mundo" ${ }^{33}$. Claramente, então, caberá à atividade científica engendrar teorias que preencham esta condição. Além disso, caberá à experiência, por meio de testes, confirmar -- ou rejeitar -- aquela estrutura, e nisto consiste a função da experiência: a de confirmar, ou rejeitar, por meio daqueles testes, a teoria. Em contrário, para o empirismo construtivo, como vimos, a ciência busca fornecer-nos teorias empiricamente adequadas, que salvem os fenômenos ${ }^{34}$. Caberá, entáo, à atividade científica encontrar regularidades observáveis e à experiência, por conseguinte, um papel central e nuclear. No entanto, vale enfatizar que para o empirismo construtivo náo é apenas da experiência que dependemos, qual uma chave que nos desvendará as regularidades fenomênicas; as teorias desempenham um papel fundamental na elaboração desses mesmos experimentos, e na elucidação dos mesmos. ${ }^{35}$ Daí que, para a comunidade epistêmica -- computada por van Fraassen como presentemente constituída pela espécie humana --, haverá distintas convicções no valor das teorias: num caso, o dos realistas, as teorias são verdadeiras -- ainda que aproximadamente --, sendo os experimentos apenas testes de confirmação ou de rejeição das mesmas; no outro, o dos empiristas construtivos, as teorias são empiricamente adequadas, e os

\footnotetext{
${ }^{32}$ Cf. VAN FRAASSEN, 1980, p. 18-19.

33 BUENO, 1999, p. 63.

${ }^{34}$ Salvar os Fenômenos é precisamente o título do capítulo 3 de The Scientific Image. É emblemático, bem como sugestivo, que van Fraassen utilize uma expressão largamente conhecida entre os antigos e os escolásticos, e também seja título de uma monografia publicada por Duhem em 1908, na qual Duhem propóe sua interpretação das teorias físicas. Não por acaso, Duhem defende que as teorias físicas não têm alcance ontológico, ou seja, aos esquemas e entidades que postulam não correspondem contrapartes reais e existentes.
} 
experimentos desempenham um papel crucial no entendimento de como se dáo as regularidades ao nível dos fenômenos. Ademais, nossa classificação sobre observabilidade depende da aceitaçáo de uma dada teoria, e nossas teorias presentes possuem uma tal complexidade e riqueza estrutural que ultrapassam em muito que o olho humano pode discernir. Tal complexidade e riqueza delineiam, até certo ponto, os aspectos observáveis -- e mensuráveis -- do mundo que elas descrevem, e o que pode ser medido é um subconjunto do total das interaçōes físicas que ocorrem na realidade. Para van Fraassen, as estruturas definíveis a partir de medições e observações são uma subclasse das estruturas físicas descritas pelas teorias, distinguindo o que é observável a partir da totalidade do que é postulado. Ora, o que é observável é para van Fraassen uma questão antropocêntrica, pois se trata do que é observado por nós seres humanos. É este o limite que nos impõem as teorias científicas, da mesma forma com que somos descritos e observados por elas.

\section{Realismo ontológico e alcance empiriológico das teorias}

Antes de apresentarmos a contraparte epistemológica que pretendemos apenas delinear neste trabalho, tomemos a seguinte proposição como hipótese: as ciências da natureza devem ser desontologizadas, isto é, não devemos buscar conhecer se nelas está presente ou não o ser, ou dito de outra forma, que as teorias tenham importe metafisico. De certa forma, portanto, podemos creditar o acerto do Círculo de Viena em haver assinalado a tomada de consciência de que a ciência moderna, em particular a física, realizou sobre si mesma: a ciência não é uma filosofia e, portanto, deve-se desontologizar o léxico científico. Por outro lado, uma segunda hipótese de trabalho se apresenta forçosamente: não tomar o conceito de fenômeno como algo que separa excessivamente a apresentaçáo sensivel relacionada com o ente real, ao mesmo tempo em que se busca uma reconstrução do mesmo a partir de uma apresentação subjetiva. Fenômeno, portanto, em nossa investigação, náo é uma aparição subjetiva, porém algo que se apresenta como constituinte da realidade, tomada precisamente segundo aspectos observáveis e mensuráveis.

${ }^{35}$ É a conhecida tese da "contaminaçăo" dos experimentos pela teoria; tese, aliás, respaldada por van Fraassen. 
Os fenômenos físicos se constituem, pois, numa manifestação do real. Ademais, a física moderna, graças a sua estrutura matemática, deixou de lado, desde o século XVII, as qualidades sensíveis aristotélicas (o frio, o calor, o úmido, o seco,e outras qualidades) como princípios de explicação, para propriedades físicas mais profundas, ainda que estas se mantenham sempre na esfera do sensível. Ademais, nem todos os fenômenos estáo no mesmo plano de realidade: todos têm um valor referencial ao real, porém nem todos eles remetem a algo situado à mesma profundidade, uma vez que de fato alguns são mais relevantes do que outros e chegam mais longe na compreensão do mundo físico. Por outro lado, este tipo de conhecimento tem como objeto material tudo aquilo que procede por meio de uma operaçáo dos sentidos (a leitura de uma escala como a de um termômetro, a observaçáo de franjas de interferência, ou a leitura de um registro espectrográfico num software especializado). Por outro lado, segundo essa perspectiva, observabilidade náo está restrita à proposta por van Fraassen, observabilidade para nós seres humanos, tomados como dispositivos de observação. Por isso, se pode associar observável a mensurável. Recordemo-nos que, em van Fraassen, medir propriedades de algo que não seja diretamente observável por nós seres humanos não é assegurar que este algo seja real, que tenha uma existência espaço-temporal, nem que a teoria que o postule estabeleça qualquer compromisso ontológico a esse respeito. É o caso, por exemplo, do elétron: o fato de que tanto a teoria eletromagnética quanto a teoria quântica lhe atribuam propriedades mensuráveis, tais como carga, massa e spin, não significa que estas propriedades calculadas sejam observáveis em si mesmas, nem que a partícula que as possua seja, igualmente, observável. Assim, o elétron e seus atributos são tipicamente inobserváveis e sua postulação por aquelas teorias não estabelece, segundo nossa hipótese de desontologização do léxico científico, qualquer compromisso ontológico com os mesmos. Assim, entendemos que o método que a ciência moderna utiliza como procedimento para salvar os fenômenos ou salvar as aparências é similar ao método utilizado pelos antigos para a formulaçáo das teorias astronômicas $^{36}$. Neste procedimento, se requer unicamente do modelo-R que as relaçóes matemáticas que contém coincidam com os valores medidos, isto é, que as conseqüências deduzidas do modelo-R sejam verificadas empiricamente. Náo se segue desta condição, no entanto, que os princípios da teoria sejam verdadeiros, nem que os símbolos ou entes teóricos

${ }^{36}$ Cf. DUHEM, 1984, p. 7-22. 
de que se vale correspondam isomorficamente a algo que tenha existência real no mundo físico. Igualmente, este procedimento que visa salvar os fenômenos não exclui, em absoluto, a investigação de relaçóes causais; supóe, no entanto, que tal investigação busque uma causalidade propriamente ontológica. Segue-se, portanto, que não podemos negar à ciência seu valor de conhecimento da realidade, mas, em contraposição a certas propostas de realismo, os enunciados que pertencem ao corpo das teorias náo refletem, como tais, a estrutura ontológica do real. ${ }^{37}$ Cremos igualmente que, até certo ponto, é esta a posição advogada por Quine ${ }^{38}$, que entende que as teorias estabelecem apenas um compromisso pragmático com respeito a tais entes teóricos, que funcionam como intermediários epistemológicos, diferindo entre si apenas segundo uma regra empírica, conforme sua proximidade maior ou menor com o tribunal da experiência.

Portanto, podemos reivindicar como hipótese que as teorias científicas procedem a uma análise empiriológica do real observável ou mensurável, em contraposição ao realismo ontológico, que sustenta a possibilidade de uma análise ontológica do real, não enquanto observável ou mensurável, mas enquanto sensível (isto é, enquanto é observável para nós, segundo van Fraassen) e dotado de inteligibilidade própria; real cuja natureza específica se encontra fora do âmbito científico, porém passível de investigação metafísica. Precisaremos em seguida em que consistem em linhas gerais cada uma dessas perspectivas, a empiriológica e a ontológica. No entanto, o detalhamento de cada tipo epistemológico de análise do real físico será objeto de artigo posterior.

Desse modo, a investigação se baseia numa distinçáo entre a análise ontológica e a análise empiriológica do real mensurável (separação que, em nosso entender, foi realizada marcadamente pelo Círculo de Viena), distinção que envolve a elaboraçáo de conceitos e o processo de análise experimental do real sensível. Um ente material qualquer, enquanto ente observável, é o ponto de partida de dois tipos de conhecimento: um, obtido por meio dos sentidos, e o outro, pela elaboração conceitual. Assim, nos deparamos com uma espécie de fluxo do real sensível que se estabiliza numa idéia ou num conceito. Dito de outro modo, ao mesmo tempo em que identificamos certas propriedades num determinado ente material

\footnotetext{
${ }^{37}$ Cf. DUHEM, 1996, p. 31-38.

${ }^{38}$ Cf. QUINE, 1980, p. 42-46.
} 
também tencionamos apreender sua natureza. Desta forma, uma dada elaboração conceitual se dá em confronto com um certo núcleo ontológico, isto é, com um certo ente real $X$, cuja tentativa de compreensão se nos apresenta através de um conjunto de propriedades que são objeto de percepção ou de observação. Há, pois, dois caminhos para se chegar ao conhecimento desse núcleo ontológico $X$ (um ente material dado qualquer): primeiramente, pela da análise do conjunto de qualidades apreendidas por meio de conceitos e definiçóes que a ele se dirigem, e que podemos chamar de análise ascendente ou ontológica, isto é, pela análise de um objeto, processo ou fenômeno a partir do qual elaboramos conceitos e definiçóes. Este tipo de análise se estrutura como um processo que tem início pela observação ou mensuração do objeto, processo ou fenômeno em sua realidade material mais concreta e individualizada, com suas propriedades sensíveis, e prossegue pela elaboração de um conceito ou definição mais geral, removido de todo aspecto sensível e quantificável, sem a presença dos aspectos individualizantes, que busca compreender qual a natureza específica deste ontológico dado, $X^{39}$. Este processo pertence mais propriamente a um realismo metafísico ou ontológico, por seu tipo característico de análise segundo Boyd ${ }^{40}$.

A outra perspectiva é obtida pela análise do conjunto das qualidades apreendidas no ente por meio do puramente observável ou mensurável, a qual podemos chamar de análise descendente ou empiriológica, isto é, a análise de um objeto, processo ou fenômeno por meio da observaçáo deste em sua realidade material mais concreta e individualizada, com suas propriedades sensíveis ou mensuráveis. Aqui se encontram sob análise todos os aspectos quantificáveis atrelados a um dado específico objeto, processo ou fenômeno. A física teórica provê por excelência os procedimentos da análise empiriológica do real quantificável. Vale frisar o seguinte: ainda que os objetos, processos ou fenômenos da experiência estejam individualizados, isto é, estejam sob a forma deste ou daquele ente ou processo específico, cujas propriedades e interaçóes com os demais de sua espécie se encontram igualmente sob observação ou mensuração, não obstante isso, se pode afirmar que a ciência sempre buscará capturar tais propriedades ou relaçóes por meio de leis gerais, aplicáveis a uma classe cada vez

\footnotetext{
39 Tal processo depende apenas indiretamente de consideraçôes adicionais sobre individualidade e identidade, as quais são particularmente sensíveis no caso dos entes submicroscópicos da física. Uma exposição bastante detalhada acerca deste dois últimos conceitos se encontra em FRENCH \& KRAUSE, 2006.

${ }^{40}$ Cf. BOYD, 1983.
} 
maior de objetos, processos ou fenômenos materiais. Por exemplo, as órbitas estacionárias do átomo de Bohr não são aplicáveis apenas a um átomo específico e individualizado (um átomo individual de hidrogênio, p. ex.), mas a todos os entes do mesmo tipo (alguns filósofos, como p. ex. Lange, chamam estes tipos de naturais $^{41}$ ). Daí se segue o caráter universal da ciência, porquanto náo visa a um determinado ente, mas a todos os entes daquele tipo ou espécie. Neste processo de conhecimento, o conteúdo ontológico permanece sempre presente, ainda que de forma indireta (seria impossível impedir que a inteligência deixe de se lhe referir através do conceito de ser), mas o que buscamos investigar, através da ciência, sáo unicamente os aspectos sensíveis, observáveis, as propriedades mensuráveis presentes nos fenômenos. A análise empiriológica é tipicamente espaço-temporal e orienta-se para o que é observável ou mensurável como tal, desempenhando, por analogia, a mesma função para o cientista que a essência desempenha para o filósofo. Quando a física postula entes de razão (entes teóricos) assim o faz para apoderar-se melhor, conforme seu modo específico de conhecer e explicar, da realidade observável. ${ }^{42}$ Com efeito, nos processos de formulação das teorias entram em jogo elementos convencionais e aspectos de idealidade. No entanto, tais convençóes são engendradas como ferramentas para podermos conhecer a realidade com respeito a seus aspectos observáveis e mensuráveis. Por isso, ocorre um constante ir e vir do ente observado ou medido ao ente teórico postulado, o primeiro estando referenciado por um conjunto de símbolos matemáticos. Assim, o modelo matemático irá sendo corrigido e ajustado para acomodar-se às mediçóes e observaçóes, de modo que se atinjam conceitualizaçóes melhores e mais adequadas. Os enunciados da física se referem diretamente aos modelos- $\mathrm{R}$ assim elaborados; no entanto, tais modelos possuem sempre, além de componentes ideais -- que são os entes teóricos e a simbologia que lhes associamos e que não encontram correspondência direta com as coisas e, portanto, se trata de referentes indiretos --, outros componentes que estáo diretamente associados a observáveis como, por exemplo, os eclipses e os planetas, que são referentes diretos em astrofísica.

\footnotetext{
${ }^{41}$ Cf. LANGE, 1996.

${ }^{42}$ Cf. MARITAIN, 1943, p.157.
} 


\section{Consideraçóes finais}

À proposta de van Fraassen em 1980 surgiram várias contraposiçôes ${ }^{43}$ que, aliadas a outras vertentes de cunho realista ${ }^{44}$, concentram-se, em geral, em apresentar alternativas à concepçáo empirista da ciência. No entanto, pode ser viável apresentar uma contraparte ao empirismo, especialmente à proposta de van Fraassen, tomando-a como modelo epistemológico do alcance da ciência, e com isso evitando um confronto direto com suas teses principais. Para isso, propóe-se uma análise da realidade natural complementar à ciência experimental; trata-se de outro tipo de enfoque, que se pode reivindicar como legítimo e justificado, se apresentando sob a forma de uma perspectiva eminentemente qualitativa ${ }^{45}$, em aditamento à análise quantitativa da ciência experimental. Várias questóes precisam ser enfrentadas para esse novo tipo de análise, a começar por se estabelecerem critérios de verdade. Por exemplo, van Fraassen apresentou em sua proposta um critério semântico que eventualmente também fornece um certo tipo de correspondência, porquanto reivindica que teorias empiricamente adequadas deveriam ser capazes de apresentar um modelo lógico para o qual fosse possível identificar subestruturas empíricas isomorfas aos fenômenos. É evidente que este tipo de adequação empírica proposto pelo empirismo construtivo supóe que a ciência demanda tanto os experimentos a serem realizados como os dados que se podem levantar a partir desses experimentos, e que a cada componente da subestrutura empírica individualmente considerada deve corresponder um conjunto de dados provenientes de observaçóes ou de medições. Porém, seria este também o caso da análise ontológica? Certamente, não. Uma investigação adicional deveria buscar, entáo, esclarecer a noção de verdade para este tipo de análise, bem como identificar as questóes metodológicas envolvidas. Estes pontos serão objeto de artigo posterior.

\footnotetext{
${ }^{43}$ Uma excelente compilação pode ser encontrada em (CHURCHLAND \& HOOKER, 1985).

${ }^{44}$ Uma interessante e ampla compilação podem ser encontradas em (PSILLOS, 1999).

45 Podem ser também utilizados métodos quantitativos nesta análise de cunho ontológico, no entanto, eles estarão sempre sob orientação e a serviço de elaboraçôes de natureza eminentemente qualitativa.
} 


\section{Referências bibliográficas}

ALSPECTOR-KELLEY, M. 2001. Should the Empiricist Be a Constructive Empiricist? Philosophy of Science, 68, 2001, p. 413-431.

AQUINO, T. 1999. Comentário ao Tratado da Trindade de Boécio - Questões 5 e 6. São Paulo: UNESP.

AYER, A. 1954. Essay on Phonomenalism. Philosophical Essays, London.

BOYD, R. 1973. Realism, Underdetermination, and a Causal Theory of Evidence. Noûs, 7.

1983. On the Current Status of Scientific Realism. Erkenntnis.

BRAITHWAITE,R. 1953. Scientific Explanation. Cambridge: Cambridge University Press.

BUENO, O. 1997. Empirical Adequacy: A Partial Structures Approach. Studies in History and Philosophy of Science, 28, p. 585-610.

--------.. 1999a. What is Structural Empiricism? Scientific Change in an Empiricist Setting. Erkenntnis 50, p. 59-85.

(Proceedings 1999), p.S474-S485.

1999c. O Empirismo Construtivo: uma reformulação e defesa. Campinas:CLE/Unicamp, 25.

2000. Empiricism, Mathematical Change and Scientific Change. Studies in History and Philosophy of Science, 31, 2000, p.269-296.

BUNGE, M. 2000. Física e Filosofia. São Paulo: Perspectiva.

CARNAP, R. 1956a. The Methodological Character of Theoretical Concepts. Minnesota Studies in the Philosophy of Science. Minneapolis.

-.-.-.-.-.-.-.-. 1956b. Empiricism, Semantics and Ontology. Meaning and Necessity. Chicago: University of Chicago Press.

CARTWRIGHT, N. 1983. How the Laws of Physics Lie. Oxford: Oxford University Press.

CHIBENI, S. 1997. Aspectos da Descrição Física da Realidade, Campinas:CLE/Unicamp, 21.

CHURCHLAND, P. 1985. The Ontological Status of Observables: in praise of the superempirical virtues. Images of Science: Essays on Realism and Empiricism. Chicago: The University of Chicago Press.

CHURCHLAND, P.; HOOKER, C. (Org) 1985. Images of Science, Chicago: The University of Chicago Press.

DEVITT, M. 1984. Realism and Truth. Oxford: Blackwell.

DUHEM, P. 1996. ARIEL,R.; BARKER, P. (Org.). Essays in the History and Philosophy of Science. Indianapolis: Hackett Publishing. 
--------. 1984. Salvar os Fenômenos. Cadernos de História e Filosofia da Ciência, Suplemento. Campinas: CLE/Unicamp.

FINE, A. 2001. The Scientific Image: twenty years after. Philosophical Studies, 106, p. $107-$ 122.

FRENCH, S.; KRAUSE, D. 2006. Identity in Physics: a historical, philosophical and formal analysis. Oxford: Clarendon Press.

FRIEDMAN, M. 1983. Foundations of Space-Time Theories. Princeton: Princeton University Press.

HARMAN, G. 1963.The Inference to the Best Explanation. Meetings of the Eastern Division of the American Philosophical Association. Washington.

5, n. 3 .

1968. Knowledge, Inference, and Explanation. American Philosophy Quaterly,

HILGEVOORT, J. (Ed.) 1994. Physics and Our View of the World. Cambridge: Cambridge University Press.

HUETTERMANN, A. 2000. Position: Bas van Fraassen. Information Philosophie, 3, p. 6873.

HUME, D. 2000. Investigaçâo acerca do Entendimento Humano. Sáo Paulo: Nova Cultural.

IRANZO, V. 2002. Constructive Empiricism and Scientific Practice: a case study. Theoria (Spain), 17, p. 335-357.

JAKI, S. 2000. The Limits of a Limitless Science and Other Essays. Wilmington: ISI Books.

KITCHER, P; SALMON, W. 1987. Van Fraassen on Explanation. The Journal of Philosophy, 84, p. 315-330.

KOCKELMANS, J. 1987. On the problem of truth in the science. Proceedings and Addresses of The American Philosophical Association, 61, 1 (Supplement), September, p. 5-26.

LADYMAN, J. Review. 1999. A novel defense of scientific realism. Jarrett Leplin. The British Journal for the Philosophy of Science, 50, p. 181-188.

LADYMAN, J. 2000. What's Really Wrong with Constructive Empiricism? Van Fraassen and the Metaphysics of Modality. British Journal for the Philosophy of Science, 51, p. 837-856.

LANGE, M. 1994. Scientific Realism and Components: The Case of Classical Astronomy. The Monist, 77, 1, La Salle (IL).

1996. Laws of Nature, Cosmic Coincidences and Scientific Realism. Australasian Journal of Philosophy, 74, 4.

-.---.---.-. 2002. The Philosophy of Physics. UK: Blackwell Publishing.

LEEDS, S. 1994. Constructive Empiricism. Synthese, 101, p. 187-221.

LEPLIN, J. (Ed) 1984. Scientific Realism. Berkeley: University of California Press.

1997. A Novel Defence of Scientific Realism. Oxford: Oxford University Press. 
MARITAIN, J. 1943. Ciencia y Filosofia. Cuatro Ensayos sobre el Espiritu en su Condición Carnal. Buenos Aires: Desclée de Brouwer.

Universitaires.

1982-2000. Les Degrés du Savoir. Oeuvres Complètes IV. Fribourg: Editions 1951. The Philosophy of Nature. New York: Philosophical Library.

---.-----.-. 1995. Distinguish to Unite or The Degrees of Knowledge. Notre Dame: University of Notre Dame Press.

MAXWELL, G. 1962. The Ontological Status of Theoretical Entities. Minnesota Studies in Philosophy of Science III.

MUSGRAVE, A. 1985. Realism versus Constructive Empiricism. Images of Science: Essays on Realism and Empiricism. University of Chicago Press.

NAGEL, J. 2000. The Empiricist Conception of Experience. Philosophy, p. 345-376.

OKASHA, S. 2000. Van Fraassen's critique of Inference to the Best Explanation. Studies in History and Philosophy of Science 31A 2000, p. 691-710.

PSILLOS, S. 1999. Scientific Realism: how science tracks truth. London: Routledge.

QUINE, W. 1980. From a Logical Point of View. 2. ed. Cambridge (MA): Harvard University Press.

REICHENBACH, H. 1938. Experience and Prediction. Chicago: University of Chicago Press. 1956. The Direction of Time. Berkeley: University of California Press.

RICH, M. 1999. Realism's new miracle? (Review of Leplin 1997). Studies in Hisory and Philosophy of Science, 30, p. 511-521.

ROSEN, G. 1994. What is constructive empiricism? Philosophical Studies, 74, 1994, p. 143178.

SALMON,W. 1998. Causal and Theoretical Explanation. Causality and Explanation. Oxford (NY).

SAVITT, S. 1993. Selective scientific realism, constructive empiricism, and the unification of theories. Midwest Studies in Philosophy, 18, p. 154-165.

SEAGER, W. 1988. Scientific anti-realism and the epistemic community. PSA, 1, p. 181-187.

SMART, J. 1966. Physical Objects and Physical Theories. Philosophy and Scientific Realism.

TELLER, P. 2001. Whither Constructive Empiricism? Philosophical Studies, 106, p. 123-150.

VAN FRAASSEN, B. 1970. On the Extension of Beth's Semantics of Physical Theories. Philosophy of Science, 37.

1980. The Scientific Image. New York: Oxford University Press.

-. 1989. Laws and Symmetry. New York: Oxford University Press.

$179-192$. 
170.

VOLLMER, S. 2000. Two kinds of observation: Why van Fraassen was right to make a distinction, but made the wrong one. Philosophy of Science, 67, p. 355-365. 